\title{
Determinants of sexual dysfunction in women with multiple sclerosis
}

\author{
Khadijeh Mohammadi ${ }^{1}$, Parvin Rahnama ${ }^{1 *}$, Sakineh Moayed Mohseni ${ }^{2}$, Mohammad Ali Sahraian ${ }^{3}$ \\ and Ali Montazeri ${ }^{*}$
}

\begin{abstract}
Background: The aim of present study was to determine disease-related and psychological risk factors for sexual dysfunction in women with multiple sclerosis (MS).

Methods: This was a clinical-based study conducted from September 2009 to June 2010 in Tehran, Iran. A consecutive sample of female patients with MS was recruited from an outpatient clinic. The Female Sexual Function Index (FSFI) was used to evaluate sexual function. In addition neurological impairment was measured using the Kurtzke Expanded Disability Status Scale (EDSS), and depression was assessed using the Beck Depression Inventory-II (BDI-II). Univariate and multiple logistic regression analyses were performed in order to examine the association between sexual dysfunction and independent variables.

Results: In all, 226 women participated in the study. Of these, 125 women (55.3\%) met the criteria for sexual dysfunction. The mean age of participants was 35.7 years $(S D=8.07)$. The results obtained from multiple logistic regression analysis indicated that the disease duration (OR for the disease duration of equal or greater than 9 years $=3.13, \% 95 \mathrm{Cl}=1.29-7.57, \mathrm{P}=0.01)$, the disease course (OR for secondary progressive $\mathrm{MS}=3.96, \% 95$ $\mathrm{Cl}=1.55-10.10, \mathrm{P}=0.004)$ and the $\mathrm{BDI}$ score $(\mathrm{OR}=1.11, \% 95 \mathrm{Cl}=1.07-1.16, \mathrm{P}<0.001)$ were significant factors contributing to sexual dysfunction in these patients.
\end{abstract}

Conclusions: The findings from this study indicated that the duration and severity of the disease in addition to depression were the most significant factors that contributed to sexual dysfunction in women with multiple sclerosis. The burden of disease and sexual dysfunction suggests the need for further attention to this patient population.

\section{Background}

Multiple sclerosis (MS) is a chronic neurological disorder that is characterized by disseminated demyelination of nerve fibers of the brain and spinal cord [1]. MS affects both male and female gender, but the disease affects women 2 to 3 times more than males [2]. Thus it is not surprising that there are many women who are suffering from the disease. MS severely destroys women's life in several aspects including disruption in sexual functioning [3-5]. The prevalence of sexual dysfunction in female patients with MS varies from 40 to $70 \%$ [6].

\footnotetext{
* Correspondence: p_rahnama1381@yahoo.com; montazeri@acecr.ac.ir ${ }^{1}$ Department of Midwifery, Faculty of Nursing and Midwifery, Shahed University, Tehran, Iran

${ }^{4}$ Mental Health Research Group, Health Metrics Research Centre, Iranian Institute for Health Sciences Research, ACECR, Tehran, Iran Full list of author information is available at the end of the article
}

Several studies demonstrated that different risk factors contribute to the development of female sexual dysfunction in MS patients including presence of physical disorders, neurological impairments, age at onset of the disease, depression and anxiety [3,7-10].

The prevalence of MS in Iranian population is estimated to be at least 51.9 per 100,000 [11]. Also, femaleto-male ratio for the disease is reported to be 3.11 [12]. Overall sexual dysfunction among Iranian females has been reported in up to $31 \%$ of women [13], but to the best knowledge of the authors prevalence of sexual dysfunction in Iranian women with multiple sclerosis is unknown.

Sexuality is a sensitive issue in almost every culture including Iran. Thus patients usually are reluctant to talk about their sexual problems and often, sexual dysfunction goes under recognized and under treated. If female sexuality is disturbed then it might lead to several

\section{() Biomed Central}

(c) 2013 Mohammadi et al.; licensee BioMed Central Ltd. This is an Open Access article distributed under the terms of the Creative Commons Attribution License (http://creativecommons.org/licenses/by/2.0), which permits unrestricted use, distribution, and reproduction in any medium, provided the original work is properly cited. 
problems, even divorce and family breakdown [14]. It also affects reproductive health and family planning. The aim of present study was to determinant disease-related and psychological risk factors for sexual dysfunction in women with multiple sclerosis (MS) in order to recognize the extent of the problem and perhaps provide appropriate guidelines for planning managed care for these patients.

\section{Methods}

\section{Design and procedure}

This was a clinical-based study conducted in Tehran, Iran, during a 9-months period from September 2009 to June 2010. A consecutive sample of 226 female patients with multiple sclerosis was recruited from the MS outpatient clinic in a large teaching and referral hospital affiliated to Tehran University of Medical Sciences. Criteria for inclusion were: diagnosis of MS according to the McDonald Revised criteria [15]; being married; having Expanded Disability Status Scale (EDSS) score less than or equal to 8 [16], and willingness to participate in the study. Exclusion criteria were: pre-existing major chronic illness, and not having sexual experience in life. All patients had a full neurologic examination.

\section{Questionnaires}

We used several questionnaires to collect data:

1. A study specific questionnaire in order to collect data on demographic, clinical, and obstetric information.

2. The Female Sexual Function Index (FSFI) was used to evaluate sexual function [17]. The FSFI is a validated and widely used 19-items self-reported measure of women's sexual function including the following dimensions: desire, arousal, lubrication, orgasm, satisfaction, and pain. The psychometric properties of the Iranian version of Female Sexual Function Index are well documented [18]. Fortunately the authors performed sensitivity analysis for the Iranian version and the cut-off point for the scale was found to be 28 (sensitivity $=83 \%$ and specificity $=82 \%$ ). In addition the same study carried out the Receiver Operating Characteristics analysis (ROC) and reported that the Area under the Curve (AUC) was 0.917. The study used the clinical diagnostic as the gold standard and reported that 28 was the best cut-off value for predicting sexual dysfunction. Thus, for the analysis purpose women who scored equal or less than 28 on the FSFI were identified as those who were suffering from sexual dysfunction. Similarly the cut-off points for the subscales also were indicated and reported as follows: Desire $=3.3$, Arousal $=3.4$, Lubrication $=3.7$, Pain $=3.8$, Orgasm $=3.4$, Satisfaction $=3.8$.
3. Depression was assessed using the Beck Depression Inventory-II (BDI-II) [19]. It is a widely used 21items self-reported measure that assesses the presence and intensity of depressive symptoms reflecting the similar symptoms suggested by the Diagnostic and Statistical Manual of Mental Disorders (DSM-IV) [20]. The Persian version of inventory already has been validated in Iran [21].

4. The neurological impairment was assessed using the Expanded Disability Status Scale (EDSS). The EDSS is a gold standard for assessment of disability in people with MS. A neurologist scored the EDSS for each patient [16]. The score on the EDSS ranges from 1 to 9.5 where scores from 1.0 to 4.5 specify that patients are fully capable of walking while higher scores indicate that patients are severely impaired.

\section{Analysis}

Descriptive analysis was carried out to explore the data. Participants were classified as with and without sexual dysfunction based on the FSFI cut-off score as mentioned earlier. We used both univariate and multiple logistic regression analyses to examine the association between dependent (sexual dysfunction) and independent variables. The level of significance was set at $5 \%$. The SPSS version 16 was used to analyze the data.

\section{Ethics}

The ethics committee of Shahed University approved the study. We obtained written informed consent from participants after comprehensive explanation of procedure involved.

\section{Results}

\section{Demographic and clinical characteristics of the study sample}

In all, 320 patients were approached and 226 participants have agreed to participate in the study, giving a response rate of $71 \%$. Overall, 125 women $(55.3 \%)$ met the criteria for sexual dysfunction. The mean age of participants was 35.7 years $(S D=8.07)$. The mean disease duration of participants was $1.8(\mathrm{SD}=0.79)$ years, and had the following diagnosis: 169 patients $(74.8 \%)$ had relapsing remitting MS (RRMS), 4 women (1.8\%) had primary progressive MS (PPMS) and 53 patients (23.5\%) had secondary progressive MS (SPMS). Frequency of sexual dysfunction was $49 \%$ in RRMS, $75 \%$ in SPMS and 50\% in PPMS. The detailed results are shown in Table 1.

\section{Risk factors for sexual dysfunction}

The association of sexual dysfunction and independent variables was first examined by univariate logistic regression analysis. The results showed that there were significant associations between sexual dysfunction and 
Table 1 Characteristics of the study sample and odds ratio for sexual dysfunction $(n=226)$

\begin{tabular}{|c|c|c|c|c|}
\hline & With SD $(n=125)$ & Without SD $(n=101)$ & OR $(95 \% \mathrm{Cl})^{*}$ & \\
\hline & No. (\%) & No. (\%) & & $\mathbf{P}$ \\
\hline Age (years) & & & & \\
\hline$\leq 35$ & $54(43.2)$ & $63(62.4)$ & 1.0 (ref.) & \\
\hline$>35$ & $71(56.8)$ & 38 (37.6) & $2.18(1.27-3.72)$ & 0.004 \\
\hline Education & & & & \\
\hline Higher & $28(22.4)$ & $41(40.5)$ & 1.0 (ref.) & \\
\hline Primary/Secondary & $97(77.6)$ & $60(59.5)$ & $2.36(1.32-4.22)$ & 0.003 \\
\hline Employment status & & & & \\
\hline Employed & $13(10.4)$ & $24(23.8)$ & 1.0 (ref.) & \\
\hline House wife & 112 (89.6) & $77(76.2)$ & $2.68(1.28-5.59)$ & 0.008 \\
\hline Duration of marriage & & & & \\
\hline$>10$ & $45(36.0)$ & $51(50.5)$ & 1.0 (ref.) & \\
\hline $10-20$ & $45(36.0)$ & 36 (35.6) & $1.41(0.78-2.56)$ & 0.250 \\
\hline $21-40$ & $35(28.0)$ & $14(13.9)$ & $2.83(1.35-5.92)$ & 0.006 \\
\hline Disease duration (ye & & & & \\
\hline $0-8$ & $82(65.6)$ & $87(86.1)$ & 1.0 (ref.) & \\
\hline$\geq 9$ & $43(34.4)$ & $14(13.9)$ & $3.25(1.66-6.39)$ & 0.001 \\
\hline Disease course & & & & \\
\hline RRMS & $83(66.4)$ & $86(85.1)$ & 1.0 (ref.) & \\
\hline PPMS & $2(1.61)$ & $2(2.0)$ & $1.03(0.14-7.52)$ & 0.972 \\
\hline SPMS & $40(32.0)$ & $13(12.9)$ & $3.18(1.59-6.83)$ & 0.001 \\
\hline EDSS score & & & & \\
\hline $0-4.5$ & 82 (65.6) & $83(82.2)$ & 1.0 (ref.) & \\
\hline $5-8$ & $43(34.4)$ & $18(17.8)$ & $2.41(1.28-4.53)$ & 0.006 \\
\hline BDI score (mean/SD) & $22.20(10.94)$ & $12.48(8.79)$ & $1.11(1.07-1.15)$ & $<0.0001$ \\
\hline
\end{tabular}

* Derived from univariate logistic regression analyses while sexual dysfunction was considered as dependent variable and other characteristics were considered as independent variable.

age $(\mathrm{OR}$ for $36-70$ years $=2.18, \% 95 \mathrm{CI}=1.27-3.72$ ), education $(\mathrm{OR}=2.42$, \%95 CI $=1.34-4.37)$, employment status (OR for housewife $=2.68, \% 95 \mathrm{CI}=1.28-5.59$ ), duration of marriage (OR for 21-40 years $=2.83$, \%95 CI = $1.35-5.92$ ), the disease duration (OR for $\geq 9$ years $=3.25$, $\% 95 \mathrm{CI}=1.66-6.39$ ), the disease course (OR for SPMS = 3.18, \%95 CI = 1.59-6.83), EDSS (OR for $5-8=2.41$, \%95 $\mathrm{CI}=1.28-4.53)$, and the $\mathrm{BDI}(\mathrm{OR}=1.11, \% 95 \mathrm{CI}=1.07$ 1.15). The results are shown in Table 1.

All significant findings in univariate analysis then were entered into a multiple logistic regression model. As shown in Table 2 the results indicated that the disease duration (OR for $\geq 9$ years $3.13, \% 95 \mathrm{CI}=1.29-7.57, \mathrm{P}=0.01$ ), the disease course (OR for secondary progressive $\mathrm{MS}=3.96$, $\% 95 \mathrm{CI}=1.55-10.10, \mathrm{P}=0.004)$ and the $\mathrm{BDI}$ score $(\mathrm{OR}=$ $1.11, \% 95 \mathrm{CI}=1.07-1.16, \mathrm{P}<0.001)$ were significant contributing factors to sexual dysfunction in these patients.

Further analyses of the data for the subscales of questionnaire (desire, arousal, lubrication, orgasm, satisfaction, and pain) are shown in Tables 3 and 4 .

\section{Discussion}

The findings from this study indicated that considering the cut-off point of 28 on the FSFI, the prevalence of sexual dysfunction among Iranian female with MS was high (55.3\%). However, one might argue that most studies

Table 2 The results obtained from multiple logistic regression analysis indicating risk factors for sexual dysfunction $(n=226)$

\begin{tabular}{llll}
\hline & & Adjusted OR (95\% Cl) & P \\
\hline Disease duration (years) & & & \\
& $0-8$ & $1.0($ ref.) & \\
& $\geq 9$ & $3.13(1.29-7.57)$ & 0.01 \\
Disease course & & & \\
& RRMS & $1.0($ ref.) & 0.85 \\
& PPMS & $1.21(0.15-9.69)$ & 0.004 \\
BDI score & SPMS & $3.96(1.55-10.10)$ & $<0.001$ \\
& & $1.11(1.07-1.16)$ & \\
& & &
\end{tabular}


Table 3 Descriptive statistics for sexual dysfunctions for subscales of the FSFI $(n=226)$

\begin{tabular}{|c|c|c|c|}
\hline & & No (\%) & Cut-off point \\
\hline \multirow[t]{4}{*}{ Desire } & & & 3.3 \\
\hline & Yes & 77 (34.1) & \\
\hline & No & $149(65.9)$ & \\
\hline & Mean score (SD) & $3.68(1.38)$ & - \\
\hline \multirow[t]{4}{*}{ Arousal } & & & 3.4 \\
\hline & Yes & $100(44.2)$ & \\
\hline & No & $126(55.8)$ & \\
\hline & Mean score (SD) & $3.38(1.75)$ & - \\
\hline \multirow[t]{4}{*}{ Lubrication } & & & 3.7 \\
\hline & Yes & $41(18.1)$ & \\
\hline & No & 185 (81.9) & \\
\hline & Mean score (SD) & $4.88(1.89)$ & - \\
\hline \multirow[t]{4}{*}{ Pain } & & & 3.8 \\
\hline & Yes & $29(12.8)$ & \\
\hline & No & $197(87.2)$ & \\
\hline & Mean score (SD) & $4.98(1.62)$ & - \\
\hline \multirow[t]{4}{*}{ Orgasm } & & & 3.4 \\
\hline & Yes & $81(35.8)$ & \\
\hline & No & $145(64.2)$ & \\
\hline & Mean score (SD) & $3.77(1.87)$ & - \\
\hline \multirow[t]{4}{*}{ Satisfaction } & & & 3.8 \\
\hline & Yes & $54(23.9)$ & \\
\hline & No & $172(76.1)$ & \\
\hline & Mean score (SD) & $4.50(1.29)$ & - \\
\hline
\end{tabular}

chose a cut-off point of lower than 26.55 for differentiating women with and without sexual dysfunction [22]. Then, our findings would have been decrease slightly. The findings also showed that there was no significant association between sexual dysfunction and age. In fact, although age was significant factor in univariate analysis (see Table 1), its effect was diminished when performing multiple logistic regression analysis. This observation might be explained by the fact that our sample consisted of women who perhaps were less sexually active. Another reason for such observation might be related to the small sample size of the study. Studying 73 MS patients a similar finding was reported by Khan et al. where they have found no association between age and sexual dysfunction as measured by the Sexual Frequency Scale [23].

The results of this study showed that duration of the disease was associated with sexual dysfunction. This implies that the more time passes, increased sexual dysfunction will occur. A study showed that the extent and the number of sexual dysfunction symptoms increased significantly in MS patients during 2-years follow-up [24]. Similarly another study revealed that duration of
Table 4 The results obtained from the logistic regression analyses for sexual dysfunctions for subscales of the FSFI $(\mathbf{n}=226)^{*}$

\begin{tabular}{|c|c|c|c|}
\hline & & $\begin{array}{l}\text { Adjusted OR } \\
(95 \% \mathrm{Cl})\end{array}$ & $\mathbf{P}$ \\
\hline \multicolumn{4}{|l|}{ Desire } \\
\hline & Age & & \\
\hline & $\leq 35$ & 1.0 (ref.) & \\
\hline & $>35$ & $2.06(1.14-3.69)$ & 0.015 \\
\hline \multicolumn{4}{|l|}{ Arousal } \\
\hline & Age & & \\
\hline & $\leq 35$ & 1.0 (ref.) & \\
\hline & $>35$ & $3.18(1.80-5.62)$ & $<0.001$ \\
\hline \multicolumn{4}{|l|}{ Lubrication } \\
\hline & Age & & \\
\hline & $\leq 35$ & 1.0 (ref.) & \\
\hline & $>35$ & $2.82(1.34-5.92)$ & 0.006 \\
\hline \multicolumn{4}{|l|}{ Pain } \\
\hline & Age & & \\
\hline & $\leq 35$ & 1.0 (ref.) & \\
\hline & $>35$ & $4.58(1.77-11.80)$ & 0.002 \\
\hline & Duration of marriage (years) & & \\
\hline & $>10$ & 1.0 (ref.) & \\
\hline & $10-20$ & $2.84(0.78-2.56)$ & 0.042 \\
\hline & $21-40$ & $2.92(1.35-5.92)$ & 0.113 \\
\hline \multicolumn{4}{|l|}{ Orgasm } \\
\hline & Age & & \\
\hline & $\leq 35$ & 1.0 (ref.) & \\
\hline & $>35$ & $2.55(1.41-4.61)$ & 0.002 \\
\hline & Disease duration (years) & & \\
\hline & $0-8$ & 1.0 (ref.) & \\
\hline & $\geq 9$ & $0.42(0.19-0.93)$ & 0.033 \\
\hline & BDI score & $1.03(1.00-1.06)$ & 0.023 \\
\hline
\end{tabular}

Satisfaction

$\begin{array}{lll}\text { Age } & & \\ \leq 35 & 1.0 \text { (ref.) } & \\ >35 & 3.44(1.70-6.96) & 0.001 \\ \text { EDSS score } & & \\ 0-4.5 & 1.0 \text { (ref.) } & \\ 5-8 & 0.33 \text { (0.11-0.95) } & 0.04 \\ \text { BDI score } & 1.04(1.00-1.07) & 0.012\end{array}$

* Derived from multiple logistic regression analysis while dysfunctions on the above subscales were treated as dependent variables and age, education, occupation, disease duration, marriage duration, disease severity, the EDSS and the BDI scores were considered as independent variables. Only the significant results are reported for each subscale. 
the disease in MS patients who suffered from sexual dysfunction was longer than the duration in MS patients without SD [25]. This might be explained by several reasons including the fact that MS could have a negative impact on relationship between patients and their sexual partners [26], and that the high levels of stress among patients' partners might affect their emotional and sexual functioning [27].

The results of this study confirmed the previous reports where it has been shown that SD was associated with progressive forms of MS [26,28]. It seems that there is a very straightforward relationship between sexual dysfunction in women with MS and progressive course of the disease.

This study also showed that depression was associated with sexual dysfunction in this population. Depression in MS is a multidimensional problem that varies by disease related impairments, activity restrictions and unpredictable prognosis $[29,30]$. Also, in patients with MS it is significantly higher than healthy individuals [31,32] and is considered as a common co-morbidity among patients with multiple sclerosis [33,34]. Consistent with our findings, other studies have reported that there was significant correlation between presence of sexual dysfunction and depression $[9,28,35]$. It has been suggested that depression may be a prominent variable contributing to the sexual difficulties in MS patients. In fact depressed women might suffer from several symptoms including affective and somatic symptoms. These symptoms all contribute to female sexual dysfunction since they might cause mood and desire disorders [36,37]. In addition, women with depression might use medication and the relationship between antidepressant medications and sexual dysfunction are well documented [38]. Studies have shown that sexual dysfunction commonly occurs during antidepressant treatment and considered as common adverse effect of antidepressant treatment [39].

\section{Limitations}

This study had some limitations. It was a cross-sectional study. Also we obtained our sample from an outpatient clinic. Thus, the results from this study must be interpreted with caution.

\section{Conclusion}

The findings indicated that sexual dysfunction was frequent in women with multiple sclerosis. The findings also indicated that clinical and psychological factors were the most important contributing variables to sexual dysfunction in women with multiple sclerosis. The burden of sexual dysfunction in addition to the disease burden suggests the need for extra attention to this patient population.
Competing interests

The authors declare that they have no competing interests.

\section{Authors' contributions}

KM was the main investigator and involved in the study design, data collection and writing process. SMM contributed to the writing process. MAS contributed to the study design and recruitment of patients. PR analyzed the data and wrote the paper. AM critically evaluated the paper, helped in analysis, responded to the reviewers' comments and provided the final manuscript. All authors read and approved the final manuscript.

\section{Acknowledgments}

The authors gratefully acknowledge the Institutional Review Board of the Shahed University, which approved and supported this project. They also wish to thank the participants for their cooperation.

\section{Author details}

'Department of Midwifery, Faculty of Nursing and Midwifery, Shahed University, Tehran, Iran. ${ }^{2}$ Department Obstetrics and Gynecology, Faculty of Medicine, Shahed University, Tehran, Iran. ${ }^{3}$ MS Research Center, Sina Hospital, Iranian Center for Neurological Research, Tehran University of Medical Sciences, Tehran, Iran. ${ }^{4}$ Mental Health Research Group, Health Metrics Research Centre, Iranian Institute for Health Sciences Research, ACECR, Tehran, Iran.

Received: 19 November 2012 Accepted: 10 July 2013

Published: 12 July 2013

\section{References}

1. Smith CR, Samkoff LM, Scheinberg LC: Clinical features, assessment and differential diagnosis of multiple sclerosis. In Multiple sclerosis: a neuropsychological disorder. Edited by Halbreich U. Washington, DC: American Psychiatric Press; 1993.

2. Noonan CW, Kathman SJ, White MC: Prevalence estimates for MS in the United States and evidence of an increasing trend for women. Neurology 2002, 58:136-138.

3. Tepavcevic D, Kostic J, Basuroski I, Stojsavljevic N, Pekmezovic T, Drulovic J: The impact of sexual dysfunction on quality of life measured by MSISQ54 in patient with multiple sclerosis. Mult Scler 2008, 14:1131-1136.

4. Nortvedt MW, Riise T, Landtblom AM, Bakke A, Nyland HI: Reduced quality of life among multiple sclerosis patients two to five years after diagnosis. Mult Scler 2001, 7:231-235.

5. McCabe MP: Relationship functioning and sexuality among people with multiple sclerosis. J Sex Res 2002, 39:302-309.

6. Bronner G, Elaran E, Golomb AD, Korczyn: Female sexuality in multiple sclerosis: the multi dimentional nature of the problem and the intervention. Acta Neurol Scand 2010, 121:289-301.

7. Barak Y, Achiron A, Elizur A, Gabbay U, Noy S, Sarova-Pinhas I: Relapsing-remitting multiple sclerosis: magnetic resonance imaging, clinical, and psychological correlates. J Psychiatry Neurosci 1996, 21:255-258.

8. McCabe MP: Exacerbation of symptoms among people with multiple sclerosis: impact on sexuality and relationships over time. Arch Sex Behav 2004, 33:593-601.

9. Zivadinov R, Zorzon M, Bosco A, Bragadin LM, Moretti R, Bonfigli L, lona LG, Cazzato G: Sexual dysfunction in multiple sclerosis: a MRI, neurophysiological and urodynamic study. J Neurol Sci 2003, 210:73-76.

10. Zivadinov R, Zorzon M, Bosco A, Bragadin LM, Moretti R, Bonfigli L, lona LG, Cazzato G: Sexual dysfunction in multiple sclerosis: II Correlation analysis. Mult Scler 1999, 5:428-431.

11. Sahraian MA, Khorramnia S, Ebrahim MM, Moinfar Z, Lotfi J, Pakdaman H: Multiple sclerosis in Iran: a demographic study of 8,000 patients and changes over time. Eur Neurol 2010, 64:331-336.

12. Elhami SR, Mohammad K, Sahraian MA, Efatekhar H: A 20-year incidence trend (1989-2008) and point prevalence (March 20, 2009) of multiple sclerosis in Tehran, Iran: a population- based study. Neuroepidemiology 2011, 36:141-147.

13. Safarinejad MR: Female sexual dysfunction in a population-based study in Iran: prevalence and associated risk factors. Interl J Impot Research 2006, 18:382-395. 
14. Kadri N, Mchichi Alami KH, Mchakra Tahiri S: Women sexual dysfunction: a population-based epidemiological study. Arch Women Ment Health 2002, 5:59-63.

15. Polman CH, Reingold SC, Edan G, Filippi M, Hartung HP, Kappos L, Lublin FD, Metz LM, McFarland HF, O'Connor PW, Sandberg-Wollheim M, Thompson AJ, Weinshenker BG, Wolinsky JS: Diagnostic criteria for multiple sclerosis: 2005 revisions to the "Mc Donald Criteria". Ann Neurol 2005, 58:840-846.

16. Kurtzke JF: Rating neurologic instrument in multiple sclerosis: an expanded disability status scale (EDSS). Neurology 1983, 33:1444-1452.

17. Rosen R, Brown C, Heiman J, Leiblum S, Meston C, Shabsigh R, Ferguson D, D'Agostino R: The female sexual function index (FSFI): a multidimensional self-report instrument for the assessment of female sexual function. J Sex Marital Ther 2000, 26:191-208.

18. Mohammadi k, Heydari M, Faghihzadeh S: The female sexual function index (FSFI): validation of the Iranian version. Payesh 2008, 7:269-278.

19. Beck AT, Steer RA, Brown GK: Manual for the beck depression inventory-II. San Antonio, TX: Psychological Corporation; 1996.

20. American Psychiatric Association: Diagnostic and Statistical Manual of Menta Disorders. 4th edition. Washington, DC: American Psychiatric Association; 1994.

21. Mohammadkhani P, Dabson KS: Psychometric characteristics of Beck Depression Inventory-II in patients with major depressive disorder. J Rehabil 2007, 29:80-86.

22. Wiegel M, Meston C, Rosen R: The female sexual function index (FSFI): cross-validation and development of clinical cut-off scores. J Sex Marital Ther 2005, 31:1-20.

23. Khan F, Pallant JF, Ng L, Whishaw M: Sexual dysfunction in multiple sclerosis. Sex Disabil 2011, 29:101-111.

24. Zorzon M, Zivadinov R, Bragadin LM, Moretti R, DeMasi R, Nasuelli D, Cazzato G: Sexual dysfunction in multiple sclerosis: a 2-year follow-up study. J Neurol Sci 2001, 187:1-5.

25. Demirkiran M, Sarica1 Y, Uguz S, Yerdelen D, Aslan K: Multiple sclerosis patients with and without sexual dysfunction: are there any differences? Mult Scler 2006, 12:209-214.

26. McCabe MP, McDonald E, Deeks AA, Vowels LM, Cobain MJ: The impact of multiple sclerosis on sexuality and relationships. J Sex Res 1996, 33:241-248.

27. Hakim EA, Bakheit AMO, Bryant TN, Roberts MWH, McIntosh-Michaelis SA, Spackman AJ: The social impact of multiple sclerosis: a study of 305 patients and their relatives. Disabil Rehabil 2000, 22:288-293.

28. Zorzon M, Zivadinov R, Bosco A, Bragadin LM, Moretti R, Bonfigli L, Morassi P, lona LG, Cazzato G: Sexual dysfunction in multiple sclerosis: a case control study. I. Frequency and comparison of groups. Mult Scler 1999 5:418-427.

29. Siegert RJ, Abernethy DA: Depression and multiple sclerosis: a review. J Neurol Neurosurg Psychiatry 2005, 76:469-475.

30. Sá MJ: Psychological aspects of multiple sclerosis. Clin Neurol Neurosurg 2008, 110:868-877.

31. Silva AMD, Vilhena E, Lopes A, Santos E, Gonçalves MA, Pinto C, Moreira I, Mendonça D, Cavaco S: Depression and anxiety in a Portuguese MS population: associations with physical disability and severity of disease. J Neurol Sci 2011, 306:66-70.

32. Barak Y, Achiron A, Elizur A, Gabbay U, Noy S, Sarova-Pinhas I: Sexual dysfunction in relapsing-remitting multiple sclerosis: magnetic resonance imaging, clinical, and psychological correlates. J Psychiatry Neurosci 1996, 21:255-258.

33. Patten SB, Beck CA, Williams JV, Barbui C, Metz LM: Major depression in multiple sclerosis: a population-based perspective. Neurol 2003, 61:1524-1527.

34. Avasarala JR, Cross AH, Trinkaus $\mathrm{K}$ : Comparative assessment of Yale single question and beck depression inventory scale in screening for depression in multiple sclerosis. Mult Scler 2003, 9:307-310.

35. Angst J: Sexual problems in healthy and depressed patients. Int Clin Psychopharmacol 1998, 13:S1-S4.

36. Steer RA, Ball R, Ranieri WF, Beck AT: Dimensions of the beck depression inventory-II in clinically depressed outpatients. J Clin Psychol 1999, 55:117-128

37. Storch EA, Roberti JW, Roth DA: Factor structure, concurrent validity, and internal consistency of the beck depression inventory-second edition in a sample of college students. Depress Anxiety 2004, 19:187-189.
38. Clayton AH, Pradko JF, Croft HA, Montano CB, Leadbetter RA, BoldenWatson C, Bass Kl, Donahue RM, Jamerson BD, Metz A: Prevalence of sexual dysfunction among newer antidepressants. J Clin Psychiatry 2002, 63:357-366.

39. Gregorian RS, Golden KA, Bahce A, Goodman C, Kwong WJ, Khan ZM: Antidepressant-induced sexual dysfunction. Ann Pharmacother 2002, 36:1577-1589.

doi:10.1186/1471-2377-13-83

Cite this article as: Mohammadi et al:: Determinants of sexual

dysfunction in women with multiple sclerosis. BMC Neurology 2013 13:83.

\section{Submit your next manuscript to BioMed Central and take full advantage of:}

- Convenient online submission

- Thorough peer review

- No space constraints or color figure charges

- Immediate publication on acceptance

- Inclusion in PubMed, CAS, Scopus and Google Scholar

- Research which is freely available for redistribution 